\section{A simple design for random light displays*}

\section{H. R. SCHIFFMAN and LEONARD W. HAMILTON \\ Rutgers. The State University \\ New Brunswick. New Jersey 08903}

The purpose of this report is to call attention to a simple means of constructing a random visual display. We have found the need in our laboratory for presenting relatively short and complex patterns of light in order to assess the effects of stimulus complexity on time perception. A solution is to employ a simple circuit capable of presenting an array of lights that flash in a random sequence (Danzis, 1965).

Figure 1 shows the basic wiring. The leads to a timer or switch provide proper experimental control over the duration interval of the display. Spacing of the lamps and their wiring is noncritical, and even the battery polarity may be reversed. Each flashing circuit consists of a neon lamp, a 0.5-MFD 200-V capacitor, and a resistor on one of four specified values, ranging from 4.7 to 8.2 megohms. Though the flashing circuits are doubled up, small capacitor and resistor mismatches provide that no two flashing circuits have the same time constant. A $47 \mathrm{~K}$ resistor connected to the common terminal of the lamp sockets insures the random nature of the flashing pattern. A listing of the required parts is given in Table 1. Observers perceive no repeated pattern or regularity in the sequence of lamp flashings. Current drain is approximately 65 micro $A$. When placed against a rear projection screen or light-diffusing glass, the bulbs are undetectable but the random flashing pattern can be seen.

A version of this design has been in use in our laboratory for about $60 \mathrm{~h}$, and its operation has been very reliable. In a study of the perceived duration of relatively brief temporal intervals (Schiffman \& Bobko. 1973), three levels or conditions of stimulus complexity were employed, each condition sampling six time intervals $(3,7,11,15,19$, and $23 \mathrm{sec})$. In all conditions, the time intervals to be estimated were specified by the duration of a display of lights controlled by an interval timer. Time estimations were made by a method of reproduction (Hornstein \& Rotter. 1969). The stimulus condition of high complexity was produced by the random lighting display described above. A stimulus condition of moderate complexity was produced by a display whose lights flashed simultaneously and at a constant interval, producing a regular and predictable display pattern. A low-complexity stimulus condition was monitored by a display whose light remained continuously lit for the duration of each interval. Based on earlier research and theory (Ornstein. 1969: Doob,

* Construction of the display was supported by funds from the Rutgers Research Council (Grant 07-2109) and the Biomedical Research Support Grant. Appreciation is due James Kidney for construction of the display.

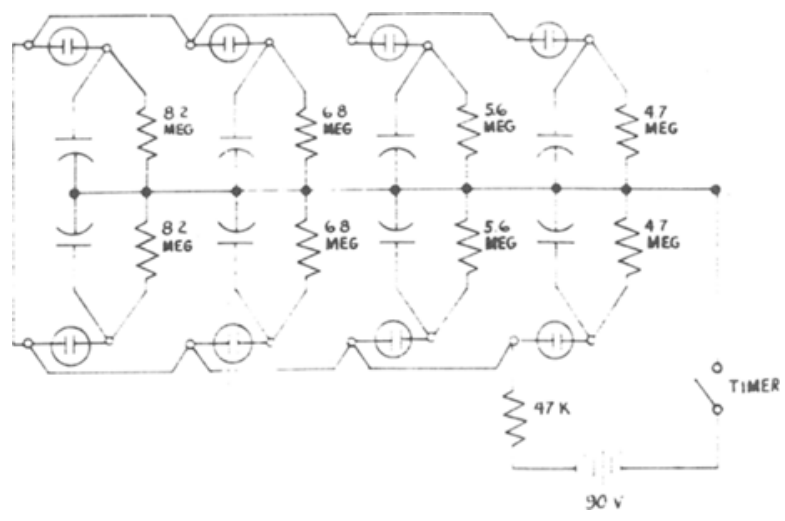

Fig. 1. Basic circuit diagram.

1971), it was predicted that the perception of relatively brief intervals of time would be affected by the complexity of stimuli defining the intervals. In this case, it was anticipated that the perceived duration of time would increase, across intervals, as stimulus complexity increased. As Table 2 shows, the prediction was basically validated.

With some additions. the capabilities of the circuit described herein can be extended. For example, linked with photocells, as described by Adamson and $\mathrm{McNab}$ (1969). it is possible to obtain random program capabilities with other stimuli and displays.

Table 1

Required Parts

$90-\mathrm{V}$ "B" battery

$0.5-\mathrm{MFD}, 200 \mathrm{~V}$ capacitors (eight)

B1 A (NE-51) neon bulbs and lamp sockets (eight each)

4.7-megohm resistor, $1 / 2 W($ two)

5.6 -megohm resistor, $1 / 2 \mathrm{~W}$ (two)

6.8-megohm resistor, $1 / 2 \mathrm{~W}$ (two)

8.2-megohm resistor. $1 / 2 \mathrm{~W}$ (two)

$47.000 \mathrm{ohm}$ resistor, $1 / 2 \mathrm{~W}$ (one)

Table 2

Time Estimations of 3-, 7-, 11-, 15-, 19-, and 23-Sec Intervals by Level of Stimulus Complexity

\begin{tabular}{cccc} 
& \multicolumn{3}{c}{ Complexity } \\
\cline { 2 - 4 } Interval & Low & Moderate & High \\
\hline 3 & 3.06 & 3.09 & 4.38 \\
7 & 7.28 & 7.14 & 8.82 \\
11 & 10.45 & 10.99 & 12.32 \\
15 & 13.65 & 14.25 & 14.55 \\
19 & 17.48 & 18.05 & 18.24 \\
23 & 20.93 & 21.62 & 21.85 \\
\hline
\end{tabular}




\section{REFERENCES}

Adamson, R., \& $\mathrm{McNab}$, L. A photoelectric sound-activated relay. Behavior Research Methods \& Instrumentation, 1969 . 1. 147 .

Danzis, A. L. Nonsense box. In Electronic experimenter's handbook. (F all ed.) New York: Ziff-Davis, 1965.

Doob, L. W. The patterning of time. New Haven: Yale University Press, 1971

Hornstein, A. D., \& Rotter, G. S. Research methodology in temporal perception. Journal of Experimental Psychology, $1969,79,561-564$.
Ornstein, R. E. On the experience of time. Middlesex, England: Penguin Books, 1969.

Schiffman, H. R, \& Bobko, D. The role of stimulus complexity on the perception of brief temporal intervals. Unpublished manuscript, Rutgers University, 1973.

(Received for publication A pril 3, 1973; revision received May 12, 1973.) 